\title{
A proposal of collaborative education for biochemistry and cell biology teaching
}

\author{
Souza-Júnior, A.A. ${ }^{1,3}$; Silva, A. P. ${ }^{1}$; Silva, T. A. ${ }^{1}$;Andrade, G. P. V. ${ }^{2}$ \\ ${ }^{1}$ Instituto Federal do Rio Grande do Norte (IFRN), Parnamirim, RN, Brazil; \\ ${ }^{2}$ Departamento de Bioquímica, UFRN, RN, Brazil. \\ ${ }^{3}$ Departamento de Bioquímica, Unifesp, São Paulo, SP, Brazil
}

\begin{abstract}
INTRODUCTION: Currently students grow up in a world of digital tools that allow you to connect instantly with the world. At the same time, teachers face several challenges to increase student interest and learning efficiency. One such challenge is the pedagogical commitment of the density of biochemistry and cell biology contents, producing a conflict scenario, between meeting content and maintain the class quality.

OBJECTIVES: From this perspective, this study aimed to evaluate the learning biochemistry and cell biology contents in high school classes of IFRN, using collaborative and digital tools in the Moodle. MATERIAL AND METHODS: The contents were offered using various tools such as video lectures, forums, questionnaires, portfolios, glossaries and electronic books. Then these tools were evaluated using an electronic form. In addition to the tools, we evaluated the platform interaction, the performance of activities and the content gamification. RESULTS: The quantitative results revealed directly proportional relationship of the interaction of Moodle with the performance of activities. The content gamification was also assessed positively, with $61 \%$ of students considered good, very good or excellent. The best evaluated tools were video lectures, with $31 \%$ preference, and questionnaires, with $24 \%$; followed by electronic book, with $10 \%$, and portfolio, with $5.5 \%$. The other tools totaled $30 \%$ of the preference. Qualitative results revealed an educational gain of content, because the student lived the experience of teaching and learning collaboratively. In addition, these tools decreased conflicts between content and schedule. CONCLUSION: Thus, the use of information and communication technology (ICT) in a collaborative learning provides relevant results, bringing the reality of the world connected to the classroom. In addition, it assists in defining the content and creative development of a strategy for the construction of the concepts applied to biochemistry and cell biology teaching.
\end{abstract}

Keywords: biochemistry teaching; collaborative education; information and communication technology. 